\title{
Anterolateral thigh flap salvage following failed deep inferior epigastric artery perforator breast reconstruction
}

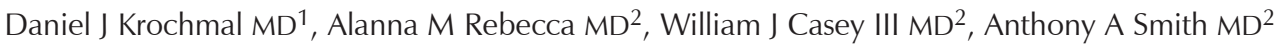

DJ Krochmal, AM Rebecca, WJ Casey III, AA Smith. Anterolateral thigh flap salvage following failed deep inferior epigastric artery perforator breast reconstruction. Can J Plast Surg 2011;19(1):2730.

The deep inferior epigastric artery perforator flap is an option for women desiring autologous tissue breast reconstruction. If this reconstruction fails, other autologous tissue flaps, including the gluteal artery perforator and latissimus dorsi flaps, may be used for salvage. The anterolateral thigh (ALT) flap offers adequate tissue volume for breast reconstruction, acceptable fat quality and a long vascular pedicle. Other advantages include obviating the need for intraoperative position changes and harvesting tissue outside of the radiation field. Two cases involving ALT flaps used in the setting of deep inferior epigastric artery perforator failure are presented with favourable results. A review of the anatomy of the ALT flap is included.

Key Words: Anterolateral thigh flap; Breast reconstruction; Deep inferior epigastric artery perforator flap

$\mathrm{T}$ he transverse rectus abdominis myocutaneous and deep inferior epigastric artery perforator (DIEP) flaps are currently the workhorses for autologous tissue breast reconstruction following mastectomy. However, situations may arise in which these flaps are not available. Contraindications to abdominal flaps include soft tissue inadequacy, previous abdominoplasty, scar presence and, controversially, plans for future pregnancy (1). Approximately $15 \%$ of women are not candidates for abdominal flap reconstruction (2). The gluteal artery perforator flap is often the second choice; however, the flap has inferior fat quality compared with abdominal flaps, offers short pedicles and necessitates an intraoperative position change (1). In these situations, the anterolateral thigh (ALT) flap has been used in breast reconstruction with satisfactory results (1-3). Simultaneous harvest of the bilateral flaps is possible, intraoperative position change is unnecessary, and the flap is soft and pliable $(1,3)$.

Wei et al (1) described five cases using ALT flaps in women with failed DIEP flaps or inadequate abdominal bulk. Overall, outcomes were rated as 'good'. Kaplan et al (2) described three cases in which women did not have adequate abdominal flaps (previous DIEP, abdominoplasty and obesity-related contraindication for DIEP). Bernier et al (3) presented a case report of bilateral breast reconstruction using bilateral ALT flaps, also with good results. We present our experience using the ALT flap for failed DIEP flap salvage.

\section{ANATOMY}

The ALT flap is of moderate thickness, with a large cutaneous area, and provides a long vascular pedicle. The flap area may be up to $21 \mathrm{~cm} \times 35 \mathrm{~cm}$ (4), with a vascular pedicle of up to $20 \mathrm{~cm} \mathrm{(5).}$ Innervation is via the anterior branch of the lateral femoral cutaneous nerve (L2-3).

The lateral femoral circumflex system usually originates from the profunda femoral artery and divides into the ascending, transverse and

\section{Sauvetage par lambeau antérolatéral de cuisse après échec d'une reconstruction mammaire au moyen d'un lambeau perforateur de l'artère épigastrique inférieure profonde}

Le lambeau perforateur de l'artère épigastrique inférieure profonde est envisageable chez les femmes qui souhaitent une reconstruction mammaire avec tissu autologue. Si cette reconstruction échoue, d'autres lambeaux de tissus autologues, dont les lambeaux perforateurs de l'artère glutéale et du latissimus dorsi peuvent être utilisés comme mesures de sauvetage. Le lambeau antérolatéral de cuisse (ALC) offre un volume tissulaire adéquat pour la reconstruction mammaire, une qualité des tissus adipeux acceptable et un long pédicule vasculaire. Entre autres avantages, il permet aussi d'éviter les changements de position peropératoires et de prélever les tissus à l'extérieur du champ d'irradiation. On présente ici deux cas de lambeaux ALC dans un contexte d'échec du lambeau perforateur de l'artère épigastrique inférieure profonde ayant donné de bons résultats. Les auteurs incluent une description de l'anatomie du lambeau ALC.

descending branches. The descending arterial branch is typically accompanied by two veins. This branch courses between the rectus femoris and vastus intermedius muscles. The first cutaneous perforator is usually the largest. It may be located near the midpoint of a line linking the anterior superior iliac spine and the superolateral patellar border. Approximately $90 \%$ of the perforators are found within $3 \mathrm{~cm}$ of this point, mostly inferolaterally (6).

Luo et al (6) detailed pedicle variations of the ALT flap. Musculocutaneous perforators course through the vastus lateralis in $80.4 \%$ of cases. Perforator arteries run intermuscularly, between the rectus femoris and the vastus lateralis, in $9.5 \%$ of cases. In $8.3 \%$ of patients, the perforator is a direct cutaneous branch from a transverse branch of the lateral circumflex femoral artery or originates directly from the lateral circumflex femoral vessel proximal to the take-off of the descending branch. Tiny cutaneous perforators with diameters of $0.2 \mathrm{~mm}$ to $0.3 \mathrm{~mm}$ are found in $1.8 \%$ of patients (6).

Case 1

\section{CASE PRESENTATIONS}

A 45-year-old woman presented with right breast T1NOMO stage I, histological grade 3, estrogen receptor negative/progesterone receptor negative, HER-2/neu negative, infiltrative ductal carcinoma. Preoperative genetic testing revealed a $20 \%$ possibility of a BRCA mutation. Her surgical history was significant for laparotomies for endometriosis. On examination, her waist measured $94 \mathrm{~cm}$ and hips measured $114.5 \mathrm{~cm}$; her breasts were a 40DD cup size (Figure 1). She desired a smaller breast size postoperatively, and elected to have bilateral mastectomies with immediate DIEP flap reconstruction.

She underwent bilateral mastectomies with right-sided sentinel lymph node biopsy. None of the 10 nodes were positive. The left abdominal DIEP flap was raised without complication. Dissection of the right abdomen demonstrated small lateral and medial perforators.

\footnotetext{
${ }^{1}$ Department of Surgery; ${ }^{2}$ Division of Plastic and Reconstructive Surgery, Mayo Clinic Arizona, Phoenix, Arizona, USA

Correspondence: Dr Daniel J Krochmal, Department of Surgery, Mayo Clinic Arizona, 5777 East Mayo Boulevard, Phoenix, Arizona 85054, USA.

Telephone 480-342-3093, fax 480-342-2866, e-mail krochmal.daniel@mayo.edu
} 

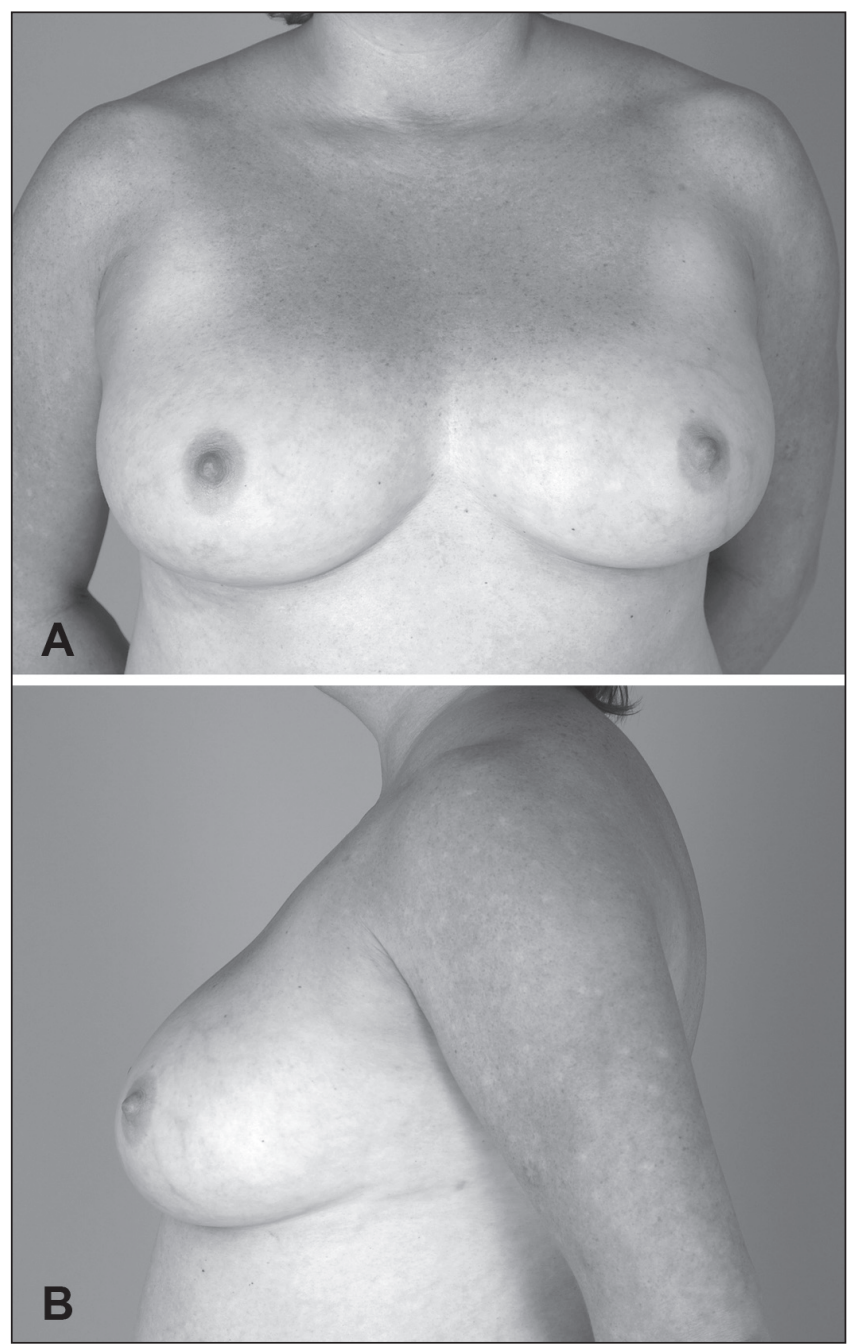

Figure 1) Case 1: Preoperative photographs showing a 40DD cup size. A Frontal view. B Left lateral view

During elevation, the perforators thrombosed at the entrance to the muscle, and the flap was deemed unsalvageable. The left abdominal DIEP flap was used for the right breast because this was the breast that would likely receive postoperative radiation. A tissue expander was placed in the subpectoral pocket of the left breast with an AlloDerm sling (LifeCell Corporation, USA) inferolaterally to prevent expander migration or extrusion.

Postoperatively, the patient experienced significant pain associated with the expander, and she desired autologous tissue for reconstruction. Multiple flaps for reconstruction were offered. An ALT flap was ultimately chosen based on the patient's body habitus and preference. Subfascial dissection of the vastus lateralis revealed an adequate proximal thigh and midthigh perforator; both were followed through the vastus lateralis to identify the lateral circumflex femoral artery. The large proximal thigh perforator allowed for a large amount of flap bulk to be used from that area. The left internal mammary artery was used for the anastomosis using 9-0 interrupted nylon sutures. A $2.5 \mathrm{~mm}$ venous coupler was used for the vein anastomosis. The skin from the flap was used as a full thickness skin graft for the donor site coverage measuring $48 \mathrm{~cm}^{2}$. Good Doppler flow was present following the procedure. She was discharged six days following the ALT flap procedure after an uneventful hospital course.

Postoperatively, she developed skin graft loss at the donor site, which necessitated a skin advancement flap for primary closure with subsequent chronic small wound formation. After six months, her left breast volume was $60 \%$ of her right breast size. The possibility of a thoracodorsal artery perforator flap for added volume was raised. Additionally,

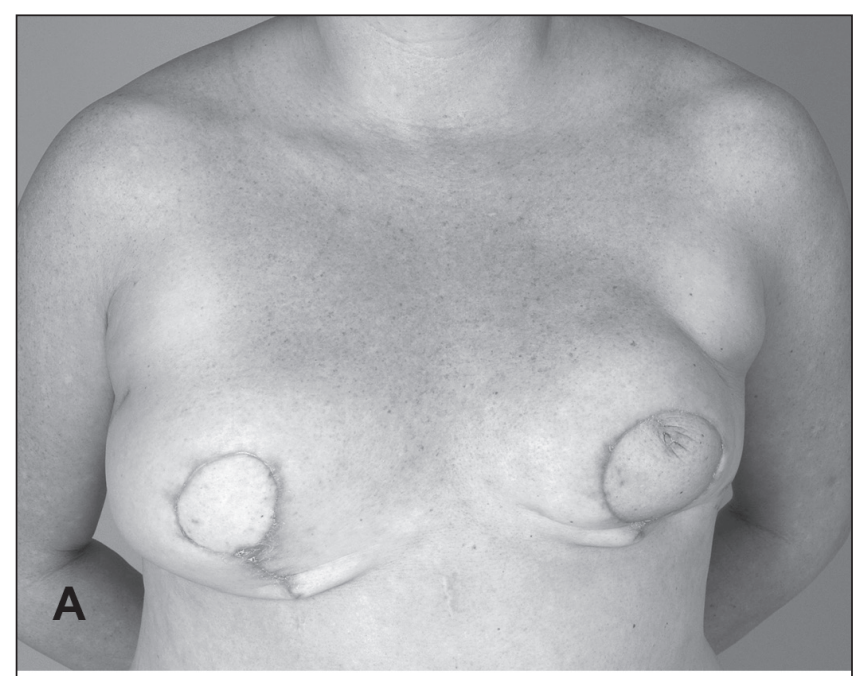

B

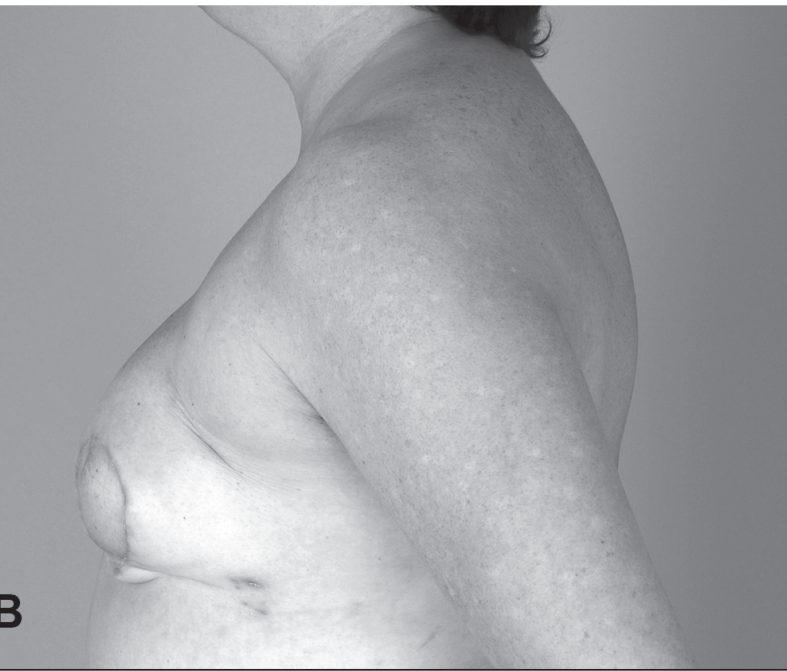

Figure 2) Case 1: Photographs 13 months postoperatively. A Frontal view demonstrating left anterolateral flap reconstruction and well-healed incisions. B Left lateral view demonstrating good breast projection

AlloDerm placement or fat injection was considered to correct a superior ridge over the left breast (Figure 2).

The patient's adjuvant chemotherapy regimen included doxorubicin, cyclophosphamide and paclitaxel. She did not tolerate paclitaxel, which was subsequently discontinued. The patient developed a recurrence in the right axillary level II and the internal mammary chain lymph nodes. While undergoing chemoradiation therapy, she developed a local recurrence in her right breast. She entered hospice care before undergoing procedures to increase her breast volume. She passed away 15 months after her mastectomy and reconstruction.

\section{Case 2}

A 67-year-old woman presented for DIEP breast reconstruction six months after bilateral mastectomies for left breast cancer. She had been undergoing breast expansion when she developed a right-sided expander staphylococcus infection, with subsequent expander removal. Her medical history was significant for hypothyroidism, depression and fibromyalgia. Her surgical history included tubal ligation and bilateral mastectomies with expander placement. Her breasts were a $38 \mathrm{C}$ to 40C cup size before mastectomy, and she desired a B cup size following reconstruction (Figure 3). The patient underwent removal of her left breast implant before DIEP reconstruction. A preoperative deep inferior epigastric artery protocol computed tomography scan demonstrated adequate bilateral perforators. 


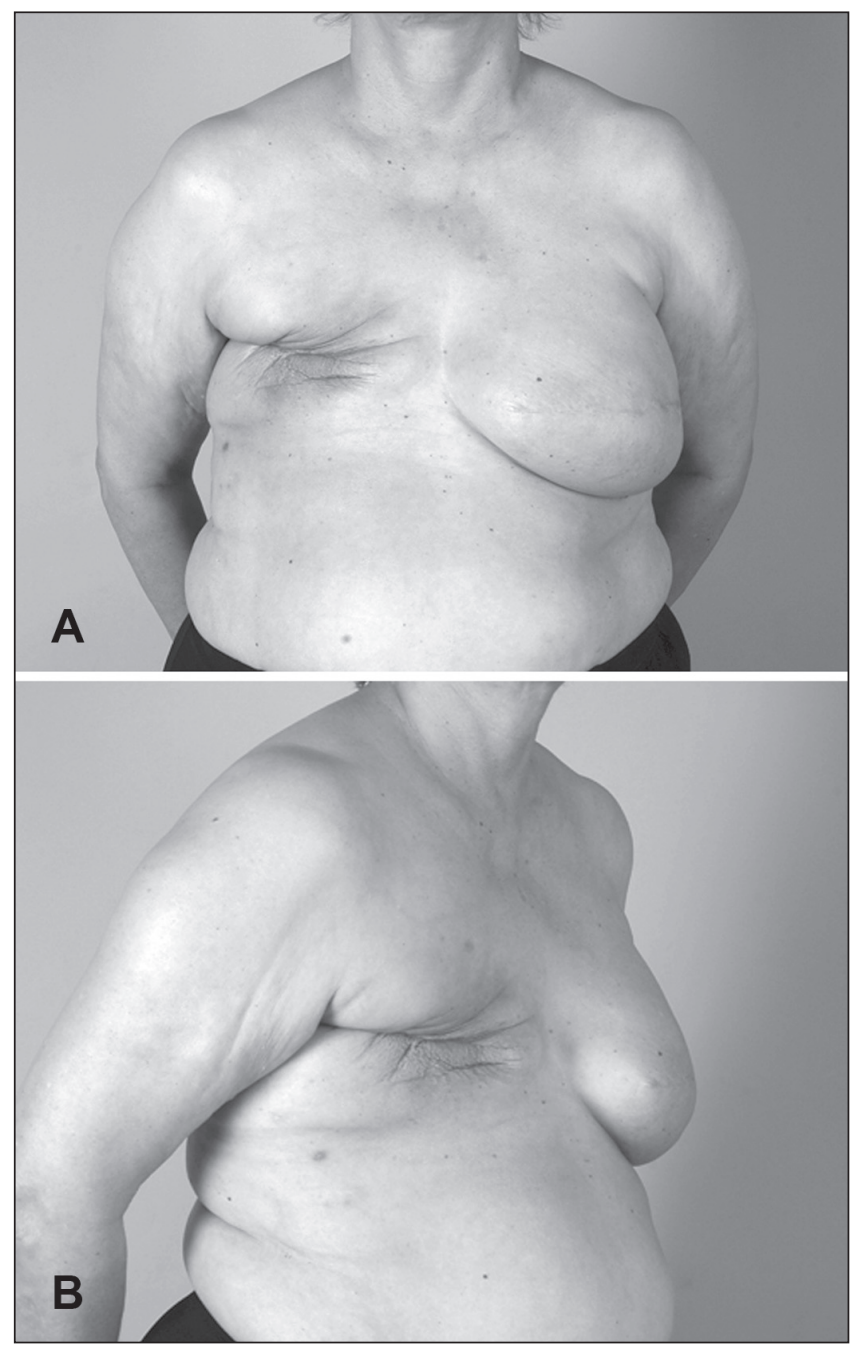

Figure 3) Case 2: Preoperative photographs showing a 38C to 40C cup size. A Frontal view. B Right oblique view

Three months after her initial presentation, she underwent bilateral DIEP breast reconstruction. The right abdomen had excellent lateral row perforators, while the left abdomen had excellent medial row perforators. The left abdominal flap, based on two medial row perforators, was anastomosed to the right internal mammary vessels at the fourth costal cartilage. Intraoperatively, adequate blood flow to the flap was lost. Flow was temporarily restored after subsequent reanastomosis; however, the flap was lost and ultimately removed two days later. On postoperative day 8 , the patient underwent left thigh ALT reconstruction. A skin paddle measuring $10 \mathrm{~cm}$ wide $\times 20 \mathrm{~cm}$ long was raised. A single perforator was traced directly into the descending branch of the lateral femoral circumflex artery. Dissection was carefully continued up to the origin of the lateral femoral circumflex artery to preserve the motor nerve to the vastus lateralis. The vascular pedicle was divided, and the flap was brought to the chest for insetting. The descending branch of the lateral femoral circumflex artery was tunnelled anterior to the clavicle and anastomosed to the transverse cervical artery using a 9-0 nylon suture. The vein was anastomosed to the external jugular vein using a $3 \mathrm{~mm}$ coupler. The flap's Doppler signal was excellent. She was discharged home four days later.

Postoperatively, the patient underwent placement of a $457 \mathrm{~mL}$ smooth round mid-range profile implant, along with debulking of excess left breast tissue for symmetry. She developed scar contracture with displacement of her implant, which was corrected with Z-plasty release. Liposuction of the right thigh improved her thigh asymmetry.

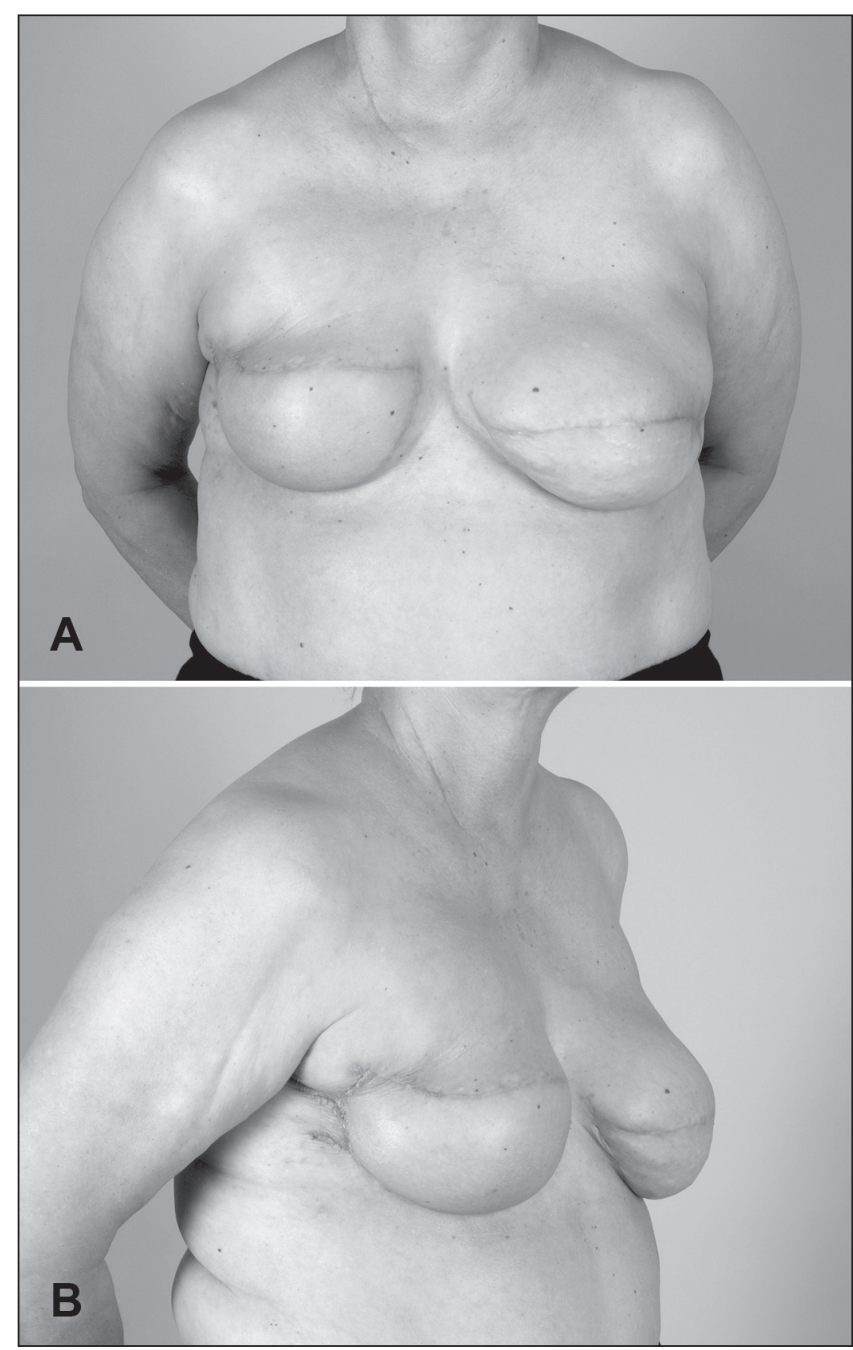

Figure 4) Case 2: Photographs eight months postoperatively. A Frontal view demonstrating adequate symmetry between right anterolateral thigh and left deep inferior epigastric artery perforator reconstructions. B Right oblique view demonstrating good breast projection and contour

The patient currently has acceptable breast symmetry, with the left side somewhat larger than the right (Figure 4). She is currently awaiting bilateral nipple-areolar reconstruction.

\section{DISCUSSION}

The ALT flap was originally described by Baek (7) in 1983, and Song et al (8) in 1984. It may be used for reconstruction of the chest wall (9), oropharynx (10-13), head and neck (14,15), hand (16-18), lower extremity (19-21), phallus (22) and abdominal wall (23). Use of the flap for breast reconstruction was originally described by Wei et al (1) in 2002.

Closing or imbricating the fascia facilitates skin closure when wound widths exceed $8 \mathrm{~cm}$, without causing a compartment syndrome (24). Kimata et al (4) detailed the morbidity of flap usage. Primary donor site closure is associated with an approximately 3\% risk of wound infection and skin necrosis. If primary closure cannot be achieved, skin grafting may be used, as in our patient. Skin grafting may contribute to decreased hip and knee range of motion in $60 \%$ of patients. Donor site dysfunction, including muscle strength, fatigue and subjective reports of weakness, are correlated with the degree of vastus lateralis damage at the time of operation. Hypertrophic scarring may be present in up to $18.8 \%$ of cases (4). 
In western Caucasian women, the transverse rectus abdominis myocutaneous and DIEP flaps are the most popular choices for autologous reconstruction. In this population, adequate soft tissue is usually not an issue, and the transverse scar is in an acceptable location for most patients. In contrast to the latissimus dorsi flap, the ALT flap is not involved in the treatment field during breast radiation, and may be preferable to women who do not desire a large back scar. In contrast to the gluteal artery perforator flap, the ALT offers a longer pedicle and does not involve intraoperative patient repositioning. The ALT flap has not been used as a primary donor site because of the resulting scar. In a series by Kimata et al (4), 69\% of patients rated the scar appearance as 'good' and 19\% as 'acceptable'. Female patients were five times more likely to rate their scar as 'poor' compared with male patients. Asymmetry between the thighs is usually not problematic because operated extremity circumference has been reported to be $89 \%$ to $100 \%$ of the contralateral thigh circumference (4).

We used the ALT flap for our patients due to previous use of their abdominal soft tissues. Although use of the flap was complicated by volume reduction and minor skin graft loss, the patient presented in case 1 was generally satisfied with her reconstruction. Similarly, the patient presented in case 2 was overall pleased with her reconstruction. The ALT flap should be considered when other breast reconstructive efforts are not indicated or desired by the patient.

FINANCIAL SUPPORT: The authors have no financial support to disclose.

\section{REFERENCES}

1. Wei FC, Suominen S, Cheng MH, Celik N, Lai YL.

Anterolateral thigh flap for postmastectomy breast reconstruction. Plast Reconstr Surg 2002;110:82-8.

2. Kaplan JL, Allen RJ, Guerra A, Sullivan SK. Anterolateral thigh flap for breast reconstruction: Review of the literature and case reports. J Reconstr Microsurg 2003;19:63-8.

3. Bernier C, Ali R, Rebecca A, Cheng MH. Bilateral breast reconstruction using bilateral anterolateral thigh flaps: A case report. Ann Plast Surg 2009;62:124-7.

4. Kimata Y, Uchiyama K, Ebihara S, et al. Anterolateral thigh flap donor-site complications and morbidity. Plast Reconstr Surg 2000;106:584-9.

5. Kimata Y, Uchiyama K, Ebihara S, Nakatsuka T, Harri K. Anatomic variations and technical problems of the anterolateral thigh flap: A report of 74 cases. Plast Reconstr Surg 1998;102:1517-23.

6. Luo S, Raffoul W, Luo J. Anterolateral thigh flap: A review of 168 cases. Microsurgery 1999;19:232-8.

7. Baek SM. Two new cutaneous free flaps: The medial and lateral thigh flaps. Plast Reconstr Surg 1983;71:354-63.

8. Song YG, Chen GZ, Song YL. The free thigh flap: A new free flap concept based on the septocutaneous artery. Br J Plast Surg 1984:37:149-59.

9. Ng RW, Li GK, Chan JY, Mak JY. Posterior chest wall reconstruction with a free anterolateral thigh flap. J Thorac Cardiovasc Surg 2007;134:537-8.

10. Farace F, Fois VE, Manconi A, et al. Free anterolateral thigh flap versus free forearm flap: Functional results in oral reconstruction. J Plast Reconstr Aesth Surg 2007;60:583-7.

11. Fernandes R. The anterolateral thigh flap in mandibular reconstruction. Atlas Oral Maxillofac Surg Clin North Am 2006;14:185-9.

12. Ozkan O, Mardini S, Chen HC, Cigna E, Tang WR, Liu YT. Repair of buccal defects with anterolateral thigh flaps. Microsurgery 2006;26:182-9.

13. Yu P, Robb GL. Pharyngoesophageal reconstruction with the anterolateral thigh flap: A clinical and functional outcomes study. Plast Reconstr Surg 2005;116:1845-55.
14. Calikapan GT, Yildirim S, Akoz T. One-stage reconstruction of large scalp defects: Anterolateral thigh flap. Microsurgery 2006;26:155-9.

15. Posch NA, Mureau MA, Dumans AG, Hofer SO. Functional and aesthetic outcome and survival after double free flap reconstruction in advanced head and neck cancer patients. Plast Reconstr Surg 2007;120:124-9.

16. Adani R, Tarallo L, Marcoccio I, Fregni U. First web-space reconstruction by the anterolateral thigh flap. J Hand Surg Am 2006;31:640-6.

17. Cong HB, Chang SM, Qiao YP, Wang CL, Sui HM, Cong L. One-stage reconstruction of complicated thumb injury with combination of microsurgical transplantations. Microsurgery 2007;27:181-6.

18. Fan CY, Jiang J, Zeng BF, Jiang PZ, Cai PH, Chung KC. Reconstruction of thumb loss complicated by skin defects in the thumb-index web space by combined transplantation of free tissues. J Hand Surg Am 2006;31:236-41.

19. Gravvanis AI, Tsoutsos DA, Karakitsos D, et al. Application of the pedicled anterolateral thigh flap to defects from the pelvis to the knee. Microsurgery 2006;26:432-8.

20. Lin CH, Lin YT, Yeh JT, Chen CT. Free functioning muscle transfer for lower extremity posttraumatic composite structure and functional defect. Plast Reconstr Surg 2007;119:2118-26.

21. Park JE, Rodriguez ED, Bluebond-Langer R, et al. The anterolateral thigh flap is highly effective for reconstruction of complex lower extremity trauma. J Trauma 2007;62:162-5.

22. Felici N, Felici A. A new phalloplasty technique: The free anterolateral thigh flap phalloplasty. J Plast Reconstr Aesth Surg 2006;59:153-7.

23. Kuo YR, Kuo MH, Lutz BS, et al. One-stage reconstruction of large midline abdominal wall defects using a composite free anterolateral thigh flap with vascularized fascia lata. Ann Surg 2004;239:352-8.

24. Rodriguez ED, Bluebond-Langner R, Park J, You X, Rosson G, Singh N. Does fascia lata repair facilitate closure and does it affect compartment pressures of the anterolateral thigh flap donor site? Plast Reconstr Surg 2007;120:1300-4. 